26 Sargeaunt $P G$, Williams JE, Bhoinani $R$, Kumate J, Jimenez E. A review of isoenzyme characterization of Entamoeba histolytica with particular reference to pathogenic and non-pathogenic stocks isolated in Mexico. Arch Invest Med (Mex) 1982:13(suppl 3):89-94.

27 Sargeaunt PG, Williams JE, Jackson TFHG, Simjee AE. A zymodeme study of Entamoeba histolytica in a group of South African school children. Trans $R$ Soc Trop Med Hyg 1982;76:401-2.

28 Sargeaunt PG, Baveja UK, Nanda R, Anand BS. Influence of geographical factors in the distribution of pathogenic zymodemes of Entamoeba histolytica: identification of zymodeme XIV in India. Trans $R$ Soc Trop Med Hyg 1984;78:96-101.

29 Gathiram V, Jackson TFHG. Frequency distribution of Entamoeba histolytica zymodemes in a rural South African population. Lancet 1985; ; $719-21$.

30 Mathews HM, Moss DM, Healy GR, Mildvan D. Isoenzyme analysis of Entamoeba histolytica isolated from homosexual men. I Infect Dis 1986;153: Entar

31 Nanda R, Baveja U, Anand BS. Entamoeba histolytica cyst passers: clinical features and outcome in untreated subjects. Lancet 1984;ii:301-3.

2 Ridley DS, Hawgood BC. The value of formol-ether concentration of faecal cysts and ova. I Clin Pathol 1956;9:74-6.

3 Sargeaunt PG. Confirmation of amoebic cyst chromatoids by wet stain after Ridley's faecal concentration. Trans $R$ Soc Trop Med Hyg 1962;56:12.
34 Robinson GL. The laboratory diagnosis of human parasitic amoebae. Trans $R$ Soc Trop Med Hyg 1968;62:285-94.

5 Nichols G, Thom BT. Screening for cryptosporidium in stools. Lancel 1984;: 735 .

36 Petri WA, Ravdin JL. Treatment of homosexual men infected with Entamoeba histolytica. $N$ Engl F Med 1986;315:393.

37 Krogstad DJ. Isoenzyme patterns and pathogenicity in amebic infection. NEnglf Med 1986;315:390-1.

38 Eisert J, Hannibal JE, Sanders SL. Fatal amebiasis complicating corticosteroid management of pemphigus vulgaris. $N$ Engl J Med 1959;261 843-5.

39 Mody VR. Corticosteroids in latent amoebiasis. Br Med J 1959;ii: 1399.

40 McAllister TA. Diagnosis of amoebic colitis on routine biopsies from rectum and sigmoid colon. Br Med $\mathcal{f} 1962 ; \mathrm{i}: 362-4$

41 Kanani SR, Knight R. Relapsing amoebic colitis of 12 years standing exacerbated by corticosteroids. BrMed I 1969;ii:613-4.

$42 \mathrm{Kanani}$ SR, Knight R. Amoebic dysentery precipitated by corticosteroids. $\mathrm{Br}$

43 Stuiver PC, Goud TJLM. Corticosteroids and liver amoebiasis. Br Med $\mathcal{J}$ 1978;ii:394-5.

(Accepted 25 May 1988)

(2)

\title{
Leukaemia and smoking habits among United States veterans
}

\author{
L J Kinlen, E Rogot
}

\begin{abstract}
The relation between leukaemia and smoking habits was examined in data from the veterans' smoking study, a prospective study of mortality among 248000 United States veterans, of whom 723 died of leukaemia during 1954-69. A significant increase in mortality from leukaemia among cigarette smokers (relative risk 1.53) was found, together with a dose-response relation with amount smoked (trend $\mathbf{p}<\mathbf{0 . 0 0 1}$ ). The relation was strongest (relative risk 1.72) for monocytic and chronic and unspecified myeloid leukaemias (ICD (7th revision) codes 204.1 and 204.2). For these leukaemias the increase was almost twofold (relative risk 1.93) among current smokers of over 20 cigarettes daily. Ex-cigarette smokers also showed an increase of leukaemia (relative risk $1.39 ; \mathbf{p}<0.001$ ).

These findings are consistent with other studies and relevant to the interpretation of minor increases of leukaemia both in population and in individual based studies. If causal they also imply that smoking is responsible for many more deaths from leukaemia in adults than all other known causes combined.
\end{abstract}

\section{Introduction}

The veterans' smoking study, a prospective study of a cohort of United States veterans initiated in 1954, has been an important source of information on the effects of smoking on mortality. ${ }^{1+4}$ In the latest published analysis (1980), covering 16 years of observation (1954-69), a more than $50 \%$ increase in mortality from leukaemia was reported among current cigarette smokers as compared with non-smokers. ${ }^{+}$In this study we have investigated the relation between smoking and leukaemia with reference to the amount and type of tobacco smoked and also to certain subtypes of the disease.

Unit, University of

Edinburgh, Edinburgh

EH8 9JZ

L J Kinlen, FRCP, director

Social and Environmental

Epidemiology Branch,

National Heart, Lung and

Blood Institute, National

Institutes of Health,

Bethesda, Maryland, USA

E Rogot, MA, statistician

Correspondence to:

Dr Kinlen. first three digits of the ICD codes. In the seventh revision of the ICD leukaemia (code 204) is subdivided into certain subtypes by the fourth digit, as follows: 204.0, lymphatic leukaemia (chronic or unspecified); 204.1, myeloid leukaemia (chronic or unspecified); 204.2, monocytic leukaemia (any type); 204.3, acute leukaemia (of any type other than monocytic); 204.4, other and unspecified leukaemia. For our study those cases with only three digits computerised were coded more completely by reference to other records which showed the full four digit codes. Mortality from each of the above subtypes was then examined among non-smokers, current cigarette smokers, ex-cigarette smokers, and cigar and pipe smokers. The numbers of deaths recorded from a given type of leukaemia in current cigarette smokers were compared with the numbers expected if the rates recorded among the non-smokers had applied. These expected numbers were calculated by applying the age specific rates among the non-smokers to the man years at risk experienced by the smokers and the results summed across the age groups covered. Observed to expected ratios were also calculated according to the amount of tobacco smoked. A similar procedure was followed for ex-smokers of cigarettes as well as for cigar and pipe smokers. Evidence of dose-response relations was sought by using a standard test for trend for cohort studies.

Finally, because the ICD (7th revision) did not distinguish the different types of acute leukaemia an attempt was made to trace as many death certificates as possible of men in the study who had died of leukaemia.

\section{Results}

During the 16 years of observation 723 men in the study died of leukaemia, of whom 330 were current cigarette smokers, 185 ex-cigarette smokers, 46 cigar or pipe smokers, and 162 non-smokers, as recorded at entry to the study. There was a significant excess of leukaemia among current cigarette smokers as compared with non-smokers (relative risk 1.53, $\mathrm{p}<0.001$ (two sided test); table I). Of the specific types examined, significant excesses were found for myeloid and monocytic leukaemias and also for lymphatic leukaemia ( $p<0.001$ (two sided) in both cases).

When the relative risk of leukaemia was examined in relation to the number of cigarettes smoked a significant dose-response effect wıs found (table II). 
TABLE I-Relative risks of leukuemia and of certain subgroups of leukuemia stratified by smoking category (95\% confidence limits in parentheses). Figures in square brackets are numbers of deaths recorded

\begin{tabular}{|c|c|c|c|c|c|}
\hline Type of leukaemia (ICD 7 th revision $)$ & Never smoked & Cigarettes & Ex-smokers & Cigars & Pipe \\
\hline Lumphatic (code 204.0)† & $1.00(0.72+0) 1.36)[n=41]$ & $1.58(1.27 \ldots 101.95)^{\star \star *}[\mathrm{n}=87]$ & $1.56(1.17 \text { to } 2.04)^{\star}[n=53]$ & $2.01(1.00$ to 3.60$)[n=11]$ & $0.83(0.17$ to 2.43$)[n=3]$ \\
\hline Monocytic and myeloidf (codes $204.1,204.2$ ) & $1.00(0.76$ to 1.29$)[\mathrm{n}=60]$ & $1 \cdot 72(1 \cdot+5 \text { to } 2 \cdot 03)^{\star \star}[n=1+4]$ & $1.54(1.22 \text { to } 1.92)^{\star \star}[n=77]$ & $1.78(0.97$ to 2.98$)[n=14]$ & $1 \cdot 18(0.43$ to $2 \cdot 57)[n=6]$ \\
\hline Acute (code 204.j) & $1.00(0.71$ to 1.36$)[\mathrm{n}=40]$ & $1.51(1.19 \text { to } 1.89)^{\star \star}[n=76]$ & $1.15(0.81$ to 1.59$)[n=37]$ & $1.53(0.66$ to 3.01$)[\mathrm{n}=8]$ & $0.85(0.17$ to 2.48$)[n=3]$ \\
\hline Other and unspecified (code 204.4) & $1.00(0.62$ to 1.53$)[n=21]$ & $0.87(0.55$ to 1.31$)[n=23]$ & $1.06(0.63$ to 1.68$)[\mathrm{n}=18]$ & $0.36(0.01$ to 2.00$)[\mathrm{n}=1]$ & \\
\hline
\end{tabular}

${ }^{\star} \mathrm{p}<0.01,{ }^{\star \star} \mathrm{p}<0.001$ (all $\mathrm{p}$ values two sided (implied $\mathrm{p}<0.1$ ).

tFor lymphatic and myeloid leukaemias chronic or unspecified.

fCalculated by approximate method (observed \pm 1.96 Vobserved) $\div$ expected).

TABLE II-Relative risks of leukaemia by subtype among current cigarette smokers by amuunt smoked ( $95 \%$ confidence limits in parentheses). Figures in square brackets are numbers of deaths recorded

Cigarettes smoked daily

\begin{tabular}{|c|c|c|c|c|c|}
\hline \multirow[b]{2}{*}{ Type of leukaemia (ICD ( 7 th revision $))$} & \multirow[b]{2}{*}{ Never smoked } & \multirow{2}{*}{\multicolumn{2}{|c|}{$10-20$}} & \multirow[b]{2}{*}{$\geqslant 21$} & \multirow[b]{2}{*}{$\chi \zeta$ trend $^{\star}$} \\
\hline & & & & & \\
\hline $\begin{array}{l}\text { Lymphatic (code } 204.0) \dagger \\
\text { Monocytic and myeloidt (codes 204.1, 204.2) } \\
\text { Acute (code 204.3) } \\
\text { Other and unspecified (code 204.4) }\end{array}$ & $\begin{array}{l}1.00(0.72 \text { to } 1.36)[n=41] \\
1.00(0.76 \text { to } 1.29)[n=60] \\
1.00(0.71 \text { to } 1.36)[n=40] \\
1.00(0.62 \text { to } 1.53)[n=21]\end{array}$ & $\begin{array}{l}1.40(0.74 \text { to } 2 \cdot 39)[n=13] \\
1.31(0.78 \text { to } 2 \cdot 07)[n=18] \\
1.67(0.94 \text { to } 2 \cdot 76)[n=15] \\
0.63(0.13 \text { to } 1.85)[n=3]\end{array}$ & $\begin{array}{l}1.76(1.29 \text { to } 2 \cdot 34)[n=47] \\
1.75(1.37 \text { to } 2 \cdot 21)[n=72] \\
1.54(1.09 \text { to } 2 \cdot 10)[n=39] \\
0.70(0.32 \text { to } 1 \cdot 32)[n=9]\end{array}$ & $\begin{array}{l}1.48(0.97 \text { to } 2 \cdot 17)[n=26] \\
1.93(1.45 \text { to } 2 \cdot 52)[n=54] \\
1.40(0.87 \text { to } 2 \cdot 11)[n=22) \\
1.40(0.70 \text { to } 2 \cdot 50)[n=11]\end{array}$ & $\begin{array}{l}5.02 ; p<0.05 \\
15 \cdot 48 ; p<0.001 \\
2.81 \\
0.13\end{array}$ \\
\hline All leukaemias & $1.00(0.85$ to $1 \cdot 17)[\mathrm{n}=162]$ & $1.34(0.99$ to $1 \cdot 77)[n=49]$ & $1.57(1.34$ to 1.83$)[\mathrm{n}=167]$ & $1.63(1.35$ to 1.97$)[n=113]$ & $21 \cdot 87 ; \mathrm{p}<0 \cdot 001$ \\
\hline Person years & 751376 & 174179 & 607355 & 434922 & \\
\hline
\end{tabular}

*All p values two sided.

†For lymphatic and myeloid leukaemias, chronic or unspecified.

Compared with non-smokers the risks were $1 \cdot 34$, 1.57 , and 1.63 for men smoking less than $10,10-20$, and 21 or more cigarettes daily respectively. In the corresponding analysis for different subtypes of leukaemia the most significant dose-response effect was found for myeloid and monocytic leukaemia $(\mathrm{p}<0.001)$, though lymphatic leukaemia also showed a significant relation $(p<0.05)$. A significant excess of leukaemia of all types combined was noted among excigarette smokers-that is, men who had stopped smoking cigarettes for reasons other than doctors' orders-the excess being only slightly lower than among current smokers (relative risk 1.39, $p<0.001$ (two sided); table I).

Cigar smokers also showed an increased mortality due to leukaemia (relative risk 1.59) but pipe smokers did not (relative risk 0.86 ), though this last estimate was based on only 12 deaths.

The seventh revision of the ICD does not separate the different types of acute leukaemia. In an attempt to remedy this deficiency a search was made for the death certificates of men who had died of leukaemia. Only 65 certificates of men who had died of acute leukaemia at ages 65-84 were found. Nevertheless, the proportion of men with acute myeloid leukaemia who were current cigarette smokers was higher $(21 / 32 ; 66 \%)$ than among those with other types of acute leukaemia $(14 / 33 ; 42 \%)$; this applied both to the age group 65-74 (17/26 (65\%) $v$ $9 / 22(41 \%))$ and to the age group $75-84(4 / 6(67 \%) v$ $5 / 11(45 \%))$. With regard to the excess among smokers of leukaemias in the category "chronic and unspecified myeloid leukaemia," there was of course, no means of knowing how many were really acute myeloid but had been crudely certified as "myeloid leukaemia."

\section{Discussion}

This study found a significant excess of leukaemia in current cigarette smokers as compared with nonsmokers together with a dose-response relation with the amount smoked. The excess was most pronounced for leukaemias coded to 204.1 and 204.2 (ICD ( 7 th revision)) - that is, those described on death certificates as chronic myeloid as well as monocytic (any type) and unspecified myeloid leukaemias. For acute leukaemias and also for other and unspecified leukaemias there was no significant excess among cigarette smokers. Consistent with these findings the dose-response relation was highly significant for myeloid and monocytic leukaemias $(p<0.001)$ but less significant for lymphatic leukaemia (and not significant for acute or other and unspecified leukaemias).

Leukaemia has in general not been regarded as a malignancy related to smoking, though a higher mortality from leukaemia among smokers has been reported in several studies and to which Austin and Cole have recently drawn attention. ${ }^{6}$ Thus an excess of similar magnitude was described both in the veterans' study ${ }^{1+}$ and in the other large prospective study of smoking in the United States by the American Cancer Society. ${ }^{i}$ Other prospective studies that included details of leukaemia found much smaller numbers of deaths from this cause-namely, 30 in a Californian study of men (relative risk 1.3 for cigarette smokers ${ }^{*}$ ) and 33 in a Japanese study of men (relative risk $0 \cdot 8^{4}$ ). The study of British doctors did not include details of deaths from leukaemia but reported only that among the 152 deaths from marrow and reticuloendothelial malignancies (in which leukaemias are grouped with myeloma and lymphomas) there was a negative relation with cigarette smoking. ${ }^{1 "}$ More than $70 \%$ of these deaths were from lymphomas and myeloma, but analysis of the 43 deaths from leukaemia yielded no sign of an excess among smokers. We note, however, that there were only 11 deaths in the non-smoking reference group ( $R$ Peto and $\mathbf{R}$ Gray, personal communication). The findings in these smaller prospective studies, though negative, would still be consistent with a moderate increase in mortality due to leukaemia associated with smoking.

A fourth prospective study (though analysed by the case-control approach) of men who had attended universities in the United States found 41 deaths from myeloid leukkaemia; a significant excess of these occurred among smokers compared with non-smokers (relative risk $2 \cdot 4$, confidence limits $1 \cdot 1$ and $5 \cdot 3$ ), but the same was not true for the 27 deaths from lymphatic leukaemia (relative risk $1 \cdot 3$, confidence limits 0.5 and 3.2)."

Few case-control studies of leukaemia have included data on smoking habits; the main exceptions were those by Williams and Hom ${ }^{12}$ and Severson..$^{13}$ In both these studies many of those approached refused to participate, so that the response rates were only 
$57 \%$ and $69 \%$ respectively, but in each an excess of myeloid leukaemia among smokers compared with non-smokers was noted.

The excess of leukaemia, and particularly myeloid leukaemia, associated with smoking in this study of 723 deaths seems unlikely to be due to chance, given both its statistical significance and the dose-response relation. Nor can it be easily attributed to underdiagnosis in the reference group (the non-smokers), given that in the United States income and education are inversely related to smoking, so that medical facilities would tend to be more, not less, available in that group. Metastases to the marrow from a bronchial carcinoma may produce a leucoerythroblastic anaemia that might be misdiagnosed as leukaemia, though hardly on the scale necessary to explain the excess found in our study. Nevertheless, and despite the dose-response relation, the magnitude of the excess is small enough for an indirect relation to be possible. We know from many studies that the diet of smokers differs from that of non-smokers in several respects, such as a higher consumption of alcohol and coffee and a lower intake of vegetables. None of these dietary constituents is known to influence the risk of leukaemia, though in one study coffee drinking was found to be associated with a higher mortality from leukaemia. ${ }^{1+}$

Biologically a relation between smoking and leukaemia is not implausible. Many constituents of tobacco smoke reach the blood, presumably including the carcinogens responsible for the increase in, say, bladder cancer. Moreover, smoking is known to affect the white cells, increasing the numbers of granulocytes, monocytes, and lymphocytes. ${ }^{15} 16$ The explanation for this leucocytosis is unknown, though the fact that there is no appreciable change in the differential white cell count weighs against chronic bronchitis as the sole cause. In this connection the fact that ex-smokers as well as current smokers show a raised white cell count ${ }^{\text {t6 }}$ is of interest in view of the increased mortality from leukaemia of both groups in this study.

Two constituents of tobacco smoke that have been linked to leukaemia may be mentioned-namely, radioactive substances and benzene. Radioactive substances can be dismissed as they can hardly be regarded as relevant to the excess of leukaemia among smokers. Radioactive substances are mainly represented by polonium-210, but the tiny amounts inhaled by smokers are much smaller than those absorbed from food. ${ }^{210} \mathrm{Po}$ from such sources makes only a small contribution to the total background irradiation of the marrow. ${ }^{17}$ It may be estimated that the ${ }^{210} \mathrm{Po}$ inhaled in cigarette smoke will increase marrow irradiation from natural background sources only by one 10th and probably less; such an increase in leukaemia is unlikely to be detectable epidemiologically. With regard to the small amounts of benzene in cigarette smoke $\left(10-100 \mu \mathrm{g}\right.$ per cigarette $\left.{ }^{6}\right)$ we do not know how the resulting blood concentrations compare with those among the benzene workers who in the past experienced substantial increases in mortality due to leukaemia. These workers were presumably exposed to much higher concentrations than those permitted under the recent United States occupational standard of $32 \mu \mathrm{g} / \mathrm{l}$ ambient air. Even this represents an exposure many times greater than that in the smoke of 20 cigarettes daily. On present evidence it seems unlikely that benzene is the sole cause of the increase of leukaemia among smokers. The question would be helped, however, by more data both on the amounts of benzene absorbed from tobacco smoke compared with the workplace and on the dose-response relation of benzene and leukaemia in occupational studies.

Finding a significant dose-response relation between myeloid leukaemia and the amount of tobacco smoked in this, the largest study of leukaemia and smoking habits to date represents additional evidence that leukaemia is a smoking related disease. In particular, this has relevance in the interpretation of minor increases in the mortality from and incidence of leukaemia in both population based and individual based studies.

This work was carried out mainly while LJK was a visiting scientist in the environmental epidemiology branch of the National Cancer Institute in 1978-9, where Dr J Fraumeni and Dr R N Hoover were unfailing in their support. Sir Richard Doll and Dr Robin Mole kindly commented on an earlier draft of the paper.

1 Dorn HF. Tobacco consumption and mortality from cancer and other diseases. Public Health Rep 1959;74:581-93.

2 Kahn HA. The Dorn study of smoking and mortality among US veterans report on $8^{1 / 2}$ years of observation. In: Haenszel W, ed. Epidemiological approaches to the study of cancer and other diseases. Bethesda, Md: National Cancer Institute, 1966:1-125. (Natl Cancer Inst Monogr No 19.)

3 Rogot E. Smoking and general mortality among US veterans, 1954-1969. Washington: Department of Health, Education and Welfare, 1974:74-544

4 Rogot E, Murray JL. Smoking and causes of death among US veterans: 16 years of observation. Public Health Rep 1980;95:213-22.

5 Breslow NE, Day NE. Comparisons among exposure groups. In: Statistical methods in cancer research. Vol 2. The design and analysis of cohort studies. methods in cancer research.

6 Austin H, Cole P. Cigarette smoking and leukaemia. $\mathcal{F}$ Chronic Dis 1986;39: $417-21$.

7 Hammond EC. Smoking in relation to the death rates of 1 million men and women. In: Haenszel W, ed. Epidemiological approaches to the study of cancer and other diseases. Bethesda, Md: National Cancer Institute, 1966:127-204. and other diseases. Bethesda, Md. Nat

8 Weir JM, Dunn JE Jr. Smoking and mortality: a prospective study. Cancer 1970;25:105-12.

9 Hirayama T. Prospective studies on cancer epidemiology based on censu population in Japan. In: Bucalossi P, Veronesi U, Cascinelli N, eds. Cancer epidemiology: environmental factors. Amsterdam: Excerpta Medica, 1975:2636. (Proceedings of XI international cancer congress, Florence. Vol 3.)

10 Doll R, Peto R. Mortality in relation to smoking: 20 years' observations on male British doctors. Br Med f 1976; ii: 1525-36.

11 Paffenburger RS Jr, Wing AL, Hyde RT. Characteristics in youth predictive of adult-onset malignant lymphomas, melanomas and leukemias. $7 \mathrm{NCI}$ 1978;60:89-92.

12 Williams RR, Hom JW. Association of cancer sites with tobacco and alcoho consumption and socioeconomic status of patients: interview study from the consumption and socioeconomic status of patients: 1 .
third national cancer survey. $7 N C I$ 1977;58:525-47.

13 Severson RK. Cigarette smoking and leukemia. Cancer 1987;60:141-4.

13 Severson RK. Cigarette smoking and leukemia. Cancer 1987;60:141-4. site-specific cancers in college men and women. INCI 1985;74:43-51.

15 Corre F, Lellough J, Schwartz D. Smoking and leukocyte-counts: results of an epidemiological survey. Lancet 1971;ii:632-4.

16 Friedman GD, Siegelaub AB, Seltzer CC, Feldman R, Collen MF. Smokin habits and the leukocyte count. Arch Environ Health 1973;26:137-43.

17 United Nations Scientific Committee on the Effects of Atomic Radiation Ionizing radiation: sources and biological effects. Annal B. Exposures to natural radiation sources. New York: UNSCEAR, 1982:83-105.

(Accepled 3 fune 1988)

\section{ONE HUNDRED YEARS AGO}

The "able editor" is proverbially infallible, and assuredly we should be the last to question his prerogative. If, however, the Achilles of the daily press has a vulnerable heel, it is to be found in the domain of medicine. The comments of the newspapers on medical topics too often tend rather to the amusement than to the edification of the professional mind. Not long ago the wildest havoc was played with the pathology and surgery of the larynx, and the spectacle, dear to the gods, was presented day after day of good men struggling with the adversity of having to "explain" matters which they themselves did not in the least understand. Now, incised wounds of the throat have taken the place of cancer, and the phrenic nerve and carotid artery that of the vocal cords and the epiglottis. An evening paper lately made the startling announcement that General Boulanger was in danger of suffocation "by haematuria in the respiratory channels!" A little time before, the Paris $F$ igaro had thrilled its readers with a sensational account of the agonies which the Emperor Frederick did not suffer, but which the French scribe thought he ought to have suffered. If the public insists on having the sickroom of distinguished patients turned into a clinical theatre for its delectation, it would be well that the demonstrators should be persons having some rudimentary knowledge of their subject. (British Medical fournal 1888;ii:135) 